\title{
Dietary Behavior Related to Cancer Prevention in a Low Income Community
}

\author{
Mona M. Abd El-Maksoud , Afaf S. Abd El-Mohsen \\ Community Health Nursing Department, Faculty of Nursing, Helwan University, Cairo, Egypt
}

Received: November 23, 2014

Accepted: December 18, 2014 Online Published: December 28, 2014

DOI: $10.5430 /$ jnep.v5n3p81

URL: http://dx.doi.org/10.5430/jnep.v5n3p81

\begin{abstract}
Background: The incidence of cancer is increasing in developing countries. Diet and cancer have a close relationship. The objectives of this study were to measure the cancer prevention-related nutrition knowledge, attitudes, and practice and barriers related to healthy food in a low income community, and to assess their cancer worries.

Subjects and methods: This cross-section descriptive study was carried out in a slum area in Cairo on a convenience sample of 414 adults permanently residing in the area. A structured interview questionnaire was used for collecting participants' sociodemographic data, knowledge about cancer, attitude and practice towards cancer dietary prevention, cancer worry scale, and the barriers preventing eating healthy food.

Results: The study revealed a wide range of participants' knowledge scores. Participants' attitude towards a healthy diet was also low. The most deficient practices were related to the intake of balanced diet and vitamins, practice of exercise, and cancer screening. The most frequent barrier to a healthy diet was taste (42\%), while the lack of information was the least (3.1\%). Multivariate analysis showed that the knowledge score was positively predicted by cancer worry score. The attitude score was positively predicted by age and knowledge score, and the practice score by married status, crowding index, and attitude score.
\end{abstract}

Conclusion: There is a poor level of knowledge and inadequate practices regarding cancer dietary prevention despite good attitudes, in addition to high worries about cancer.

Implications for practice: There is urgent need for awareness raising intervention programs for dietary prevention of cancer.

Key Words: Cancer, Diet, Knowledge, Attitude, Practice, Barrier

\section{Introduction}

Cancer is the leading cause of death in economically developed countries and the second leading cause of death in developing ones. It is predicted that by 2020 , the number of new cases of cancer in the world will increase to more than 15 million, with deaths increasing to 12 million. ${ }^{[1]}$ The incidence of cancer is increasing in developing countries as a result of population aging and growth as well as the in- creasing adoption of cancer-associated lifestyle as smoking, physical inactivity, and "westernized" diets. ${ }^{[2]}$ In fact, all adenocarcinomas are linked to a Westernized lifestyle. ${ }^{[3]}$

In the Middle-East, the literature regarding cancer registration data and associated epidemiological findings are scarce. The available data indicate that the incidence rates are rising; with the continued population growth. ${ }^{[4]}$ In Egypt, in 2005 there were 20,326 new patients seen at the National

\footnotetext{
*Correspondence: Mona M. Abd El-Maksoud; Email: Drmona158@gmail.com; Address: Community Health Nursing Department, Faculty of Nursing, Helwan University, Cairo, Egypt.
} 
Cancer Institute (NCI), Cairo University, with more than 14,000 hospital admissions, and approximately 170,000 outpatient visits. NCI is the main cancer Institute in Egypt which is located at Cairo and receive cancer cases from all 28 Governorates of Egypt. In addition, Galal reported that there is a more tendency to westernized diet in Egypt and westernization of the life style during the past three decades with significant lifestyle changes into sedentary shape and the diets became rich in fat and meat, with poor cereals and fibers typical of Western population. ${ }^{[3,5]}$

The close relationship between diet and cancer is suggested by the large variation in rates of specific cancers in different countries. ${ }^{[6]}$ It has been estimated that approximately $35 \%$ of cancer deaths could be prevented by appropriate diet. ${ }^{[7]}$ Healthy lifestyle behaviors for cancer risk reduction include healthy diet, weight management, regular exercise, and smoking cessation. ${ }^{[8]}$ Strategies to change people's nutrition-related cancer prevention cognitions could impact dietary behavior and ultimately decrease cancer rates. ${ }^{[9]}$ Accordingly, several public health programs emphasizethe benefits of good nutrition to motivate people to improve their diets. ${ }^{[10]}$

Clinicians, public health professionals, and policy makers can play an active role in accelerating the application of such interventions. ${ }^{[2,11]}$ Public health nurses have the ability to serve as change agents in strengthening cancer control within the systems they practice. They can engage in a number of cancer control activities such as providing public education on cancer risk, prevention, and early detection, and in development of policy in support of cancer control activities. ${ }^{[12]}$ This is of particular importance in disadvantaged communities with low levels of education and insufficient resources living in slum areas, which lack basic municipal services and where poverty and illiteracy prevail. Therefore, the aim of this study was to measure the cancer preventionrelated nutrition knowledge, attitudes, and practice and barriers related to healthy food in a low income community, and to assess their cancer worries.

\section{Subjects and methods}

\subsection{Design and setting}

A cross-section descriptive design was used in this study, which was carried out in a slum area (Istabl-Antar) in Misr El Kadema district, one of Cairo's poorest and most crowded slums.

\subsection{Study subjects}

A convenience sample of 414 subjects was recruited with the selction criteria of being adult (18 years or older) and permanently residing in the study setting. No exclusion criteria were set. The sample size was calculated to estimate any prevalence of deficient knowledge, attitude, or practice related to dietary habits of $50 \%$ or higher, with $95 \%$ level of confidence and an absolute precision of 5\%, with a compensation for a non-response rate of about $5 \%$, using the Epi-Info software package.

\subsection{Data collection tool}

A structured interview questionnaire was developed by researchers in Arabic language for collecting data. It was composed of 6 parts:

- Socio-demographic data: such as age, sex, education, marital state, income, number of family members, crowding index, residence of origin, etc.

- Knowledge about cancer: This consisted of 18 True/false questions asking about the nature of cancer and related sik factors such as "are all tumors malignant?" "High fat diet is protective", "smoking causes lung cancer only", etc. Additonally, there was a list of 50 food items. The respondent had to classify each item as "protective", "risky" or "unrelated to cancer. For scoring, a correct response was scored 1 and the incorrect 0 or I do not know 0 . The points attained in each area of knowledge (cancer and risk factors; risky food; protective food; unrelated food) were divided by the total number of items of the area and converted into a percent score. Then calculation of the mean, standard devistion, and median of each area and of the total knowledge was done.

- Attitude towards cancer dietary prevention: The researchers developed an attitude scale consisting of 12 questions to measure participant's attitudes towards dietary cancer prevention. It included statements as "I think cancer has no relation to diet," "cancer is not preventable", "I like fats even if they are carcinogenic". The responses were on a 5-point Likert scale ranging from "strongly agree" to "strongly disagree." For scoring, these were given 5 to 1 points respectively. The scoring was reversed for negative items so that a higher score reflects a more positive attitude towards dietary cancer prevention.

- Practice: In this part, the participant was asked about the frequency of practicing some risky (as eating fast food, excess fats, etc.), or protective (eatring fruits and vegetables and high fiber diet) dietary habits, in addition to other risky (smoking or drinking) or protective (exercise, vitamins) habits. Each positive habit practiced was scored one point, and the negative habit inversely scored. The total practice score was calculated by summing up the points attained so that a higher score reflects a more healthy or less risky practice.

- Cancer worry scale: This is a 6-item scale designed to measure worry about the risk of developing cancer and the impact of worry on daily functioning. It was originally developed by Lerman et al. $(1994)^{[13]}$ 
and recently modified by Hopwood et al. (2001), ${ }^{[14]}$ with a high level of reliability (Cronbach's alpha for the full scale: 0.86). In these questions the participant rates the extent of worry about getting cancer on a scale never to a lot. Examples of questions are: "How many times you think you will develop cancer?" "Do these thoughts interfere with your daily life activities?". The scale items are scored from 1 (no worry) to 4 (maximum worry) for each of the six items. The total score was converted into a percent score.

- Barriers prevent eating healthy food: This last section include 8 questions asking the participant about the barriers facing eating healthy food as cost, availability, lack of knowledge, and family/friends influences.

The researchers developed the data collection tool based on a review of literature relevant to the problem. The tool was then reviewed rigorously by a panel of experts from nursing and medical related specialties such as community health, nutrition, and oncology for face and content validation.

\subsection{Pilot study}

A pilot study was carried out on a sample 50 participants in a similar slum area in order to test the clarity of the questions and to estimate the time needed for data collection and the necessary modifications. The pilot helped the researchers to have a similar approach in asking questions and interviewing. The pilot also served to test the reliability of the scale used assessing their internal consistency. They showed good reliability with Conbach's alpha coefficient 0.91 for the attitude scale and 0.87 for the cancer worry scale. The tool was finalized based on the pilot study results, and the pilot sample was not included in the main study sample.

\subsection{Ethical clearance}

The study protocol was approved by the faculty pertinent committees. All principles of ethics in research were applied. The researchers obtained verbal consent for participation from each subject after explaining the aim of the study, and the right to refuse or withdraw. Total confidentiality of any obtained information was ensured, and these were to be used only for the research purpose. Moreover, the researchers catched the opportunity of the interview to provide health education messages and materials to the participants.

\subsection{Data collection}

This study fieldwork was a door-to-door household survey of a geographically-defined community. The participants were consecutively recuited according to the eligibility criteria. The process was pursued until the required sample size was achieved. At the end of the interview, the researchers provided the participants with an illustrative colored booklet aimed at raising their awareness about healthy dietary practices for cancer prevention. The time spent with each participant to fill the forms ranged from 30 to $45 \mathrm{~min}$. The data collection process was done in the morning time during the period from April to June 2013. This might explain the higher percentage of women in the sample due to more availability during the time of data collection.

\subsection{Statistical analysis}

Data entry and statistical analysis were done using SPSS 16.0 statistical software package. Data were presented using descriptive statistics in the form of frequencies and percentages for qualitative variables, and means and standard deviations and medians for quantitative variables. Cronbach alpha coefficient was calculated to assess the reliability of the developed tools through their internal consistency. Spearman rank correlation was used for assessment of the interrelationships among quantitative variables and ranked ones. In order to identify the independent predictors of the scores of knowledge, attitude, and practice multiple linear regression analysis was used after testing for normality, and homoscedasticity, and analysis of variance for the full regression models were done. Statistical significance was considered at $p<.01$.

\section{Results}

The study included 414 subjects, mostly females $(77.5 \%)$, in an age range 18 to 71 years, with median 41 years (see Table 1). Illiterates and those who could read and write constituted about two-thirds of the sample. The majority of the sample was married (91.5\%), unemployed (74.9\%) and of urban residence of origin ( $88.9 \%)$. Slightly less than half of them were having insufificent income (46.9\%).

Table 2 shows a wide range of participants' knowledge scores. The highest areas of knowledge were those related to risky and protective foods, with median scores 60.9 and 63.6 out of a maximum of 100 . In total, the median score was 52 out of 100, which means that half of the participants had a score of less than 52, pointing to low level of knowledge.

Regarding the participants' attitudes towards a healthy diet, Table 3 indicates high scores with a median reaching 86.7 out of a maximum of 100 . As for safe practice, the median score was low, 50.0 out of 100 . The most deficient practices were related to the intake of balanced diet and vitamins, practice of exercise, as well as cancer screening which was practiced by none of the participants. Meanwhile, the cancer worry score ranged between 20.9 and 100, with a median 70.8 out of 100 . 
Table 1: Socio-demographic characteristics of participants in the study sample $(n=414)$

\begin{tabular}{|c|c|c|}
\hline Socio-demographic Characteristics & Frequency & $\%$ \\
\hline \multicolumn{3}{|l|}{ Age (years) } \\
\hline$<40$ & 193 & 46.6 \\
\hline $40-$ & 138 & 33.3 \\
\hline $50+$ & 83 & 20.0 \\
\hline Range & $18.0-71.0$ & \\
\hline Mean \pm SD & $41.2 \pm 10.9$ & \\
\hline Median & 41 & \\
\hline \multicolumn{3}{|l|}{ Gender } \\
\hline Male & 93 & 22.5 \\
\hline Female & 321 & 77.5 \\
\hline \multicolumn{3}{|l|}{ Education } \\
\hline Illiterate & 177 & 42.8 \\
\hline Read/write & 95 & 22.9 \\
\hline Basic (elementary) & 94 & 22.7 \\
\hline Intermediate (high school) & 39 & 9.4 \\
\hline High (University) & 9 & 2.2 \\
\hline \multicolumn{3}{|l|}{ Job } \\
\hline Employee & 14 & 3.4 \\
\hline Worker & 90 & 21.7 \\
\hline Retired/unemployed & 310 & 74.9 \\
\hline \multicolumn{3}{|l|}{ Current marital status } \\
\hline Unmarried & 35 & 8.5 \\
\hline Married & 379 & 91.5 \\
\hline \multicolumn{3}{|l|}{ Residence of origin } \\
\hline Rural & 46 & 11.1 \\
\hline Urban & 368 & 88.9 \\
\hline \multicolumn{3}{|l|}{ Crowding index } \\
\hline$<2$ & 177 & 42.8 \\
\hline $2+$ & 237 & 57.2 \\
\hline \multicolumn{3}{|l|}{ Income } \\
\hline Insufficient (in debt) & 194 & 46.9 \\
\hline Just sufficient with no debt or saving & 167 & 40.3 \\
\hline Sufficient and saving & 53 & 12.8 \\
\hline
\end{tabular}

Table 2: Knowledge about cancer and nutrition among participants in the study sample $(n=414)$

\begin{tabular}{ll}
\hline Knowledge & \\
\hline Knowledge of Cancer and Risk Factors & $27.8-88.9$ \\
Range & $53.8 \pm 13.8$ \\
Mean \pm SD & 55.6 \\
Median & \\
Knowledge of Risky Food Items & $0.0-87.0$ \\
Range & $47.0 \pm 29.0$ \\
Mean \pm SD & 60.9 \\
Median & \\
Knowledge of Protective Food Items & $0.0-90.9$ \\
Range & $45.8 \pm 37.9$ \\
Mean \pm SD & 63.6 \\
Median & \\
Knowledge of Unrelated Food Items & $0.0-100.0$ \\
Range & $45.3 \pm 43.8$ \\
Mean $\pm S D$ & 42.5 \\
Median & \\
Total knowledge & $33.5-71.2$ \\
Range & $49.9 \pm 9.6$ \\
Mean $\pm S D$ & 52.0 \\
Median & \\
\hline
\end{tabular}


Table 3: Total scores of attitude and practice towards healthy diet and cancer worry scale

\begin{tabular}{|c|c|}
\hline \multicolumn{2}{|l|}{ Items } \\
\hline \multicolumn{2}{|l|}{ Attitud } \\
\hline Range & $40.0-100.0$ \\
\hline Mean \pm SD & $88.2 \pm 11.6$ \\
\hline Median & 86.7 \\
\hline \multicolumn{2}{|l|}{ Safe Practice } \\
\hline Eat balanced diet & $28(6.8 \%)$ \\
\hline Avoid excess risky food items (fast food, high fat, excess meat) & $397(95.9 \%)$ \\
\hline No smoking & $392(94.7 \%)$ \\
\hline No alcohol & $388(93.7 \%)$ \\
\hline No drug addiction & $389(94.0 \%)$ \\
\hline Exercise $30+\min / 3+$ days per week & $4(1.0 \%)$ \\
\hline Take vitamins & $1(1.4 \%)$ \\
\hline Practice cancer screening & $0(0.0 \%)$ \\
\hline Practice of hygienic habits & $273(65.9 \%)$ \\
\hline \multicolumn{2}{|l|}{ Total score $(\max =100)$} \\
\hline Range & $0.0-85.7$ \\
\hline Mean \pm SD & $47.6 \pm 10.7$ \\
\hline Median & 50.0 \\
\hline \multicolumn{2}{|l|}{ Cancer Worry Scale } \\
\hline Range & 20.9-100.0 \\
\hline Mean \pm SD & $61.6 \pm 20.9$ \\
\hline Median & 70.8 \\
\hline
\end{tabular}

As Table 4 illustrates, the most frequently mentioned barrier to a healthy diet was taste $(42 \%)$, followed by lack of encouragement from others $(22.5 \%)$. The cost was less re- ported $(14.3 \%)$, while the lack of information was the least agreed upon barrier $(3.1 \%)$.

Table 4: Barriers to healthy diet as reported by participants in the study sample $(n=414)$

\begin{tabular}{|c|c|c|c|c|c|c|}
\hline \multirow{3}{*}{ Barriers to Healthy Food } & \multicolumn{6}{|c|}{ Opinions } \\
\hline & \multicolumn{2}{|c|}{ Agree } & \multicolumn{2}{|c|}{ Uncertain } & \multicolumn{2}{|c|}{ Disagree } \\
\hline & No. & $\%$ & No. & $\%$ & No. & $\%$ \\
\hline Taste & 174 & 42.0 & 8 & 1.9 & 232 & 56.0 \\
\hline No encouragement from others & 93 & 22.5 & 11 & 2.7 & 310 & 74.9 \\
\hline Cost & 59 & 14.3 & 18 & 4.3 & 337 & 81.4 \\
\hline Not available & 46 & 11.1 & 30 & 7.2 & 338 & 81.6 \\
\hline Preparation not easy & 27 & 6.5 & 8 & 1.9 & 379 & 91.5 \\
\hline Conflicting messages & 20 & 4.8 & 30 & 7.2 & 364 & 87.9 \\
\hline Promotions and ads & 19 & 4.6 & 46 & 11.1 & 349 & 84.3 \\
\hline Lack of information & 13 & 3.1 & 10 & 2.4 & 391 & 94.4 \\
\hline
\end{tabular}

Table 5 demonstrates moderate statistically significant positive correlations between the scores of attitude and each of the knowledge and practice, and between the scores of knowledge and cancer worry scale. On the other hand, the scores of practice bear moderate statistically significant negative correlations with those of knowledge and cancer worry scale. This latter is also significantly negatively correlated with the attitude score $(r=-0.417)$.
In multivariate analysis (see Table 6), the statistically significant independent positive pedictors of the knowledge score were subject's female gender, urban residence, income, and cancer worry score. Conversely, age, education, and unmarried status significant independent negative predictors of the score. As the model reveals, income is the most influencing predictor as shown by the standardized coefficient, and the model explains $58 \%$ of the variation in the knowledge score. 
Table 5: Correlation matrix of various scale scores

\begin{tabular}{llll}
\hline \multirow{2}{*}{ Scales } & \multicolumn{2}{l}{ Spearman's Rank Correlation Coefficient } & Practice \\
\cline { 2 - 4 } & Knowledge & Attitude & Cancer Worry \\
\hline Knowledge & & & \\
Attitude & $.494^{* *}$ & $.320^{* *}$ & $-.359^{* *}$ \\
Practice & $-.185^{* *}$ & $-.417^{* *}$ & \\
Cancer worry & $.355^{* *}$ & &
\end{tabular}

Table 6: Best fitting multiple linear regression model for the knowledge, attitude and practice scores

\begin{tabular}{|c|c|c|c|c|c|c|c|}
\hline & \multicolumn{2}{|c|}{ Unstandardized Coefficients } & \multirow{2}{*}{$\begin{array}{l}\text { Standardized } \\
\text { Coefficients }\end{array}$} & \multirow{2}{*}{ t-test } & \multirow{2}{*}{$p$} & \multicolumn{2}{|c|}{ 95\% Confidence Interval for B } \\
\hline & B & Std. Error & & & & Lower & Upper \\
\hline \multicolumn{8}{|l|}{ Knowledge Score } \\
\hline Constant & 40.49 & 3.62 & & 11.19 & $<.001$ & 33.38 & 47.60 \\
\hline Age & -0.19 & 0.03 & -0.22 & -5.79 & $<.001$ & -0.25 & -0.13 \\
\hline $\begin{array}{l}\text { Sex } \\
\text { (reference: male) }\end{array}$ & 1.81 & 0.78 & 0.08 & 2.31 & .02 & 0.27 & 3.35 \\
\hline Education & -1.19 & 0.29 & -0.14 & -4.14 & $<.001$ & -1.75 & -0.62 \\
\hline $\begin{array}{l}\text { Marital status } \\
\text { (reference: unmarried) }\end{array}$ & -2.29 & 1.14 & -0.07 & -2.01 & .049 & -4.53 & -0.05 \\
\hline $\begin{array}{l}\text { Residence of origin } \\
\text { (reference: rural) }\end{array}$ & 2.41 & 1.04 & 0.08 & 2.31 & .02 & 0.36 & 4.46 \\
\hline Income & 6.42 & 0.55 & 0.46 & 11.69 & $<.001$ & 5.34 & 7.50 \\
\hline Cancer worry score & 0.09 & 0.02 & 0.20 & 5.66 & $<.001$ & 0.06 & 0.12 \\
\hline
\end{tabular}

$r^{2}=0.58$, Model ANOVA: $F=19.48, p<.001$

Variables entered and excluded: job, crowding index, have cancer, family history of cancer

\begin{tabular}{|c|c|c|c|c|c|c|c|}
\hline \multicolumn{8}{|l|}{ Attitude Score } \\
\hline Constant & 116.87 & 5.29 & & 22.09 & $<.001$ & 106.47 & 127.28 \\
\hline Age & 0.16 & 0.05 & 0.15 & 3.13 & $<.001$ & 0.06 & 0.25 \\
\hline $\begin{array}{l}\text { Sex } \\
\text { (reference: male) }\end{array}$ & -11.31 & 2.07 & -0.41 & -5.46 & $<.001$ & -15.39 & -7.24 \\
\hline Education & -0.92 & 0.46 & -0.09 & -2.02 & .04 & -1.82 & -0.03 \\
\hline $\begin{array}{l}\text { Residence of origin } \\
\text { (reference: rural) }\end{array}$ & -4.11 & 1.54 & -0.11 & -2.66 & .01 & -7.14 & -1.07 \\
\hline Cancer worry score & -0.14 & 0.03 & -0.25 & -5.66 & $<.001$ & -0.19 & -0.09 \\
\hline Knowledge score & 0.21 & 0.06 & 0.18 & 3.34 & $<.001$ & 0.34 & 0.09 \\
\hline
\end{tabular}

$r^{2}=0.36$, Model ANOVA: $F=33.41, p<.001$

Variables entered and excluded: marital status, income, crowding index, have cancer, family history of cancer

Practice Score

$\begin{array}{llllllll}\text { Constant } & 33.05 & 7.25 & & 4.56 & <.001 & 18.79 & 47.30 \\ \begin{array}{l}\text { Marital status } \\ \text { (reference: unmarried) }\end{array} & 5.52 & 2.19 & 0.11 & 2.51 & .01 & 1.20 & 9.83 \\ \text { Crowding index } & 3.92 & 1.26 & 0.14 & 3.10 & <.001 & 1.43 & 6.40 \\ \text { Attitude score } & 0.28 & 0.06 & 0.24 & 4.85 & <.001 & 0.17 & 0.39 \\ \text { Cancer worry score } & -0.15 & 0.03 & -0.22 & -4.62 & <.001 & -0.21 & -0.08\end{array}$

$r^{2}=0.24$, Model ANOVA: $F=27.01, p<.001$

Variables entered and excluded: age, sex, education, income, residence, have cancer, family history of cancer, knowledge score

As regards the attiude score, the same table illustrates that subject's age and knowledge score were the statistically significant independent positive pedictors of the attitude score. On the other hand, female gender, education, urban resi- dence, and cancer worry score were significant negative independent predictors of this score. As the model shows, gender is the most influencing predictor as shown by its standardized coefficient, and the model explains $36 \%$ of the 
variation in the attitude score.

Concerning practice score, the table indicates that its statistically significant independent positive pedictors were subject's married status, crowding index, and attitude score, while the cancer worry score was the sole significant independent negative predictor of the score. The model demonstrates that the attitude score is the most influencing predictor as indicated by its standardized coefficient, and the model explains $24 \%$ of the variation in the practice score.

\section{Discussion}

The incidence of cancer reaches its maximum in developed countries in view of the aging of the population, urbanization and adoption of industrialized lifestyle. Dietary factors play an important role in the high incidence of several types of cancer. Modification of dietary habits to include anticancer and anti-inflammatory foods thus represent a promising approach to preventing the development of cancer. ${ }^{[15,16]}$ The present study assessed the knowledge, attitudes, and practices related to dietary cancer prevention, the barriers to healthy food intake, and the cancer worries in a sample of a low income slum community. The findings generally point to low knowledge and practice despite generally high attitude scores.

The study findings point to low scores of knowledge among participants, with almost half of them reaching about $50 \%$ of the total attainable knowledge score. Many of them could not correctly identify protective and risky food items or those not related to cancer. The finding is in agreement with studies that similarly reported general lack of knowledge with many important gaps among adults in Mexico ${ }^{[17]}$ and Italy. ${ }^{[18]}$ On the same line, Shihab et al. (2012) found that only $57.8 \%$ of the study subjects in Jordan identified healthy diets. ${ }^{[19]}$ Meanwhile, a study in India by Seth et al.(2005) found a higher level of knowledge with more than half of the subjects having good knowledge pertaining to cancer. ${ }^{[20]}$

This knowledge deficiency revealed in the present study is expected given the sample characteristics with a majority having no education, and mostly living in crowded residences and having insufficient income. In fact, the multivariate analysis revealed that an urban residence of origin and a higher income positively predicted the knowledge score. Similar findings were revealed in a study in Congo where knowledge was significantly influenced by the place of residence and marital status. ${ }^{[21]}$ However, our finding that education was a negative predictor is paradoxical, and incongruent with this study. This might be explained by the generally low level of education in the sample. It might also be due to interviewer's bias where less educated people may try to impress the interviewer, providing him/her with what he/she wants or expects.

Published by Sciedu Press
The knowledge score of the current study participants was also better among females and those who are married. This might be attributed to the fact that women are responsible for purchasing and preparing food for their families especially when married. This may lead to improvement in their dietary knowledge through the TV cooking programs, which do provide some information about healthy food. In line with this, a study carried out in the United States $^{[22]}$ found that food preparers were predominately married (88\%), and females (94\%). Additionally, in a US study, demonstrated a significant improvement in dietary knowledge of fruit and vegetable recommendations following a TV cooking show. ${ }^{[23]}$

Despite the low level of knowledge revealed among the participants of the present study, their attitudes towards a healthy diet were high, with more than half of them having more than $80 \%$ of the maximum attitude score. These high scores may reflect good intentions among the participants, but may also be due to the bias of self-reporting in interviewing where the respondent tries to impress the interviewer by over-reporting positive attitudes. Nonetheless, and in congruence with these results, approximately half of respondents endorsed positive nutrition-related cancer prevention cognitions by stating that cancer can be prevented through good nutrition. ${ }^{\text {9] }}$ Meanwhile, a lower attitude rate in a study in India, where $50 \%$ of the participants were having a positive attitude towards functional foods. This difference could be due to the fact that this latter study was carried out on cancer patients whose attitudes might be negatively affected by their illness. ${ }^{[24]}$

According to the present study, the attiude score tended to be higher with older age and a higher knowledge score. However, as for knowledge, it was paradoxically negatively related to the educational level, which might have the same explanation of the majority of low education in the study sample. The positive influence of knowledge is quite plausible given that attitudes are often modulated by cognition. Also, the attitudes may improve with advancing age since the perception of risks also increase with age, and consequently may have a positive impact on attitude. In line with this, people are motivated to act when they perceive they are at risk, and this is the basis of the risk perception attitude framework. ${ }^{[25]}$ Similarly, Shah and Jain found a positive correlation between participants' knowledge and attitudes towards healthy dietary habits. ${ }^{[26]}$ Moreover, the relation with age is in agreement with the study from China were the scores of knowledge and attitude positively correlated with age. ${ }^{[27]}$

As regards practice, the present study demonstrated major deficiencies. These were most evident regarding the intake of balanced diet and vitamins, practice of exercise, and cancer screening. The practice score was virtually inflated by the high percentages of participants reporting no smoking or addiction, and avoiding excess fast food, which are ex- 
pected in a sample of low income mostly female participants. This deficient practice of healthy dietary and other associated habits may be related to certain barriers, mainly related to taste and social pressures. This might be attributed to craving to the taste of meat and animal proteins which these people cannot afford due to economic reasons. In line with this identified deficient healthy practices, low consumption of fruits, non-starchy vegetables and unprocessed cereals in daily meals in a sample of African Americans. ${ }^{[27]}$ As for the low intake of vitamins, this is certainly attributed to the low socio-economic level of the present study sample. The results disagree with other studies reporting higher percentages of the population taking supplements and multivitamins in more affluent countries. ${ }^{[28,29]}$

However, the cost of healthy food and the lack of information were not among the most frequently mentioned barriers to good nutritional practices in the present study. This might be attributed to the fact that generally the cancer protective food items as vegetables and legumes are less costly compared with the risky items such as meat and animal fat. However, it is the problem of taste, which is stressed by the participants given their low income, craving to the taste of meats and other animal products, and dislike of the daily poor food they are used to eat. The finding is in partial agreement with Bovell-Benjamin et al. ${ }^{[30]}$ whose study in Sudan found cultural traditions was a major barrier to changing food habits. However, the cost was also mentioned as an important barrier.

The multivariate analysis of the present study identified better practices among married participants and those with higher attitude scores. The better practice of the married has been previously explained with the knowledge score. As for the positive influence of attitude on practice, it is quite understandable since behaviors are most often fostered by related attitudes. In fact, the knowledge score had no direct influence on practice but this was rather through its effect on the attitude score. In congruence with this, the perceived risk in terms of feelings rather than as a purely cognitive probability judgment that predict health behaviors. ${ }^{[31]}$

The present study has also revealed high cancer worry scores among the participants. The finding is in congruence with what reported in a Sudanese study where most participants were fearful of cancer, associating it with death. Moreover, the multivariate analysis of the present study identified the cancer worry score as an independent significant negative predictor of the attitude and practice scores. ${ }^{[32]}$ This means that excess worries about cancer may have a deleterious effects on the individual's intentions and actual behavior, which is expected since morbid anxiety often leads to indifferent attitudes and uncaring practices.

\section{Conclusion and recommendations}

Our results reveal a poor level of knowledge and inadequate practices regarding cancer dietary prevention despite good attitudes, in addition to high worries about cancer. The main barriers to healthy foods are related to food taste and social pressures. Therefore, there is urgent need for awareness raising intervention programs for dietary prevention of cancer; these may include cooking classes for women to improve the taste of mainly vegetable food items. These programs can even be introduced early to children and adolescents at school level. Further research is proposed to assess the effectiveness of interventions in improving knowledge and behavior for cancer prevention and control, However, the study results need to be interpreted considering its limitations, which are mainly related to the possibility of interviewer's bias and the over-representation of women in the sample.

\section{Conflicts of Interest Disclosure}

The author declares that there is no conflict of interest statement.

\section{References}

[1] Ferlay J., Shin H.R., Bray F., Forman D., Mathers C.D., and Parkin D. GLOBOCAN 2008, Cancer Incidence and Mortality Worldwide: IARC Cancer Base No. 10. Lyon, France: International Agency for Research on Cancer; Year.2010.

[2] 0Jemal A., Bray F., Melissa M., Ferlay J. Global Cancer Statistics. CA CANCER J CLIN. 2011; 61(2): 69-90. PMid:21296855 http://dx.doi.org/10.3322/caac. 20107

[3] Galal O.M. The nutrition transition in Egypt: obesity, under nutrition and the food consumption context. Public Health Nutr. 2002; 5(1): 141-8. PMid:12027277

[4] Salim E., Moore M.A., Al-Lawati J.A., and Al-Sayyad J. Cancer Epidemiology and Control in the Arab World - Past-Present and Future. Asian Pacific Journal of Cancer Prevention. 2009; 10: 3-16. PMid:19469617
[5] Elattar I. Cancer Statistics, NCI Egypt. 2007.

[6] Danaei G., Vander Hoorn S., Lopez A.D., Murray C.J.L., and Ezzati M. The Comparative Risk Assessment Collaborating Group (Cancers). Causes of cancer in the world: comparative risk assessment of nine behavioural and environmental risk factors. Lancet. 2005; 366(19). 1784-93. http://dx.doi.org/10.1016/S0140 -6736(05) 67725-2

[7] Shankar S., Klassen, A.C., Garrett E., and Houts P.S. Evaluation of a nutrition education intervention for women residents of Washington, DC, public housing communities. Health education research. 2007; 22(3): 425-437. PMid:16982649 http://dx.doi.org/10.1093 /her/cyl092

[8] Khan N., Afaq F., and Mukhtar H. Lifestyle as risk factor for cancer: Evidence from human studies. Cancer Lett. 2010; 293(2): 133-143. 2.

[9] Sullivan H.W., Beckjord E.B, Finney L.J., and Hesse B.W. 
Nutrition-Related Cancer Prevention Cognitions and Behavioral Intentions: Testing the Risk Perception Attitude Framework. Health EducBehav. 2008; 35(6): 866-879. PMid:19011220 http://dx.d oi.org/10.1177/1090198108326164

[10] Stables G.J, Subar A.F., Patterson B.H. Changes in vegetable and fruit consumption and awareness among US adults: results of the 1991 and 1997 5-a-Day for Better Health Program surveys. J Am Diet Assoc. 2002; 102(6): 809-817. http://dx.doi.org/10.10 16/S0002-8223(02) 90181-1

[11] Kanavos P. The rising burden of cancer in the developing world. Annals of Oncology. 2006; 17(8): 15-23.

[12] Ayres C.G. Said Another Way Nurses' Role in Cancer Control. Nursing Forum. 2009; 44(1): 64-67. PMid:19187055 http://dx .doi.org/10.1111/j.1744-6198.2009.00128.x

[13] Lerman C., Kash K., and Stefanek M. Younger women at increased risk for breast cancer: perceived risk, psychological well-being and surveillance behaviour. Monogr Natl Cancer Inst. 1994; 16: 171176. PMid:7999461

[14] Hopwood P., Shenton A., Lalloo F., Evans D.G.R., and Howell A Risk perception and cancer worry: an exploratory study of the impact of genetic risk counselling in women with a family history of breast cancer. J Med Genet. 2001; 38: 139. http://dx.doi.org /10.1136/jmg.38.2.139

[15] Béliveau R., and Gingras D. Role of nutrition in preventing cancer. Can Fam Physician. 2007; 53: 1905-1911. PMid:18000267

[16] El Hattab O. H., and Nouh M. Epidemiology of cancer.National Cancer Institut. 2012.

[17] Pérez-Contreras I., Allen B., Ruiz-Velasco S., Schiavon-Errnani R., Cruz-Valdez A., Hernández C., and Lazcano-Ponce E. Levels and correlates of knowledge about cancer risk factors among 13,293 public school students in Morelos, Mexico. PrevMed. 2004; 39(2): 286-99. PMid:15226037 http://dx.doi.org/10.1016/j .ypmed. 2004.04.001

[18] Sessa A., Abbate R., Giuseppe G., Marinelli P., and Angelillo I.F. Knowledge, attitudes, and preventive practices about colorectal cancer among adults in an area of Southern Italy. BMC Cancer. 2008; 8: 171. PMid:18547435 http://dx.doi.org/10.1186/1471-2 407-8-171

[19] Shihab R.A., Obeidat N.A., Bader R.K., Shtaiwi A., Ayub A., and Hawari F. Cancer-related knowledge, attitudes, and risk perception among 6 grade students in Jordan, Stud Health Technol Inform. 2012; 172: 155-60. PMid:22910516

[20] Seth T., Kotwal A., Thakur R., Singh P., and Kochupillai V. Common cancers in India: knowledge, attitudes and behaviors of urban slum dwellers in New Delhi. Public Health. 2005; 119(2): $87-$ 96. PMid:15694955 http://dx.doi.org/10.1016/j.puhe.20 04.05 .013

[21] Ali-Risasi C., Mulumba P., Verdonck K., Vanden Broeck D. and Praet M. Knowledge, attitude and practice about cancer of the uterine cervix among women living in Kinshasa, the Democratic Republic of Congo. BMC Womens Health. 2014; 14(1):
30. PMid:24548698 http://dx.doi.org/10.1186/1472-687 4-14-30

[22] Brown J.L., and Wenrich T.R. Intra-family role expectations and reluctance to change identified as key barriers to expanding vegetable consumption patterns during interactive family-based program for Appalachian low-income food preparers. J Acad Nutr Diet. 2012; 112(8): 1188-200. PMid:22818727 http://dx.doi.org/10.10 $16 / \mathrm{j} \cdot \mathrm{j}$ and .2012 .05 .003

[23] Clifford D., Anderson J., Auld G., and Champ J. Good Grubbin': Impact of a TV cooking show for college students living off campus. J Nutr Educ Behav. 2009; 41(3): 194-200. PMid:19411053 http://dx.doi.org/10.1016/j.jneb.2008.01.006

[24] Shah P., and Jain S. Study on Awareness Regarding Consumption of Functional Foods With Reference To Cancer Prevention. IOSR Journal of Nursing and Health Science (IOSR-JNHS. 2012; 1(1): 45-48. http://dx.doi.org/10.9790/1959-0114548

[25] Rimal R. N., and Real K. Perceived risk and efficacy beliefs as motivators of change: Use of the risk perception attitude (RPA) framework to understand health behaviors. Human Communication Research. 2003; 29: 370-399.

[26] Tan C., Luo J.Y., Wang Z., Mou J.S., Zhang L.L., Fu C.H., et al. Knowledge, attitude, practice and related determinants on nutrition among caregivers of rural stranded children under 7-year-olds in China. [Article in Chinese] Zhonghua Liu Xing Bing Xue Za Zhi. 2009; 30(6): 588-91. PMid:19957625

[27] Bovell-Benjamin A., Dawkins N., Pace R., and Shikany J.M. Dietary Consumption Practices and Cancer Risk in African Americans in the Rural South. Journal of Health Care for the Poor and Underserved. 2010; 21(3): 57-75. PMid:20675946 http://dx.doi.org $/ 10.1353 / \mathrm{hpu} .0 .0361$

[28] Radimer K.L. National nutrition data: contributions and challenges to monitoring dietary supplement use in women. J Nutr. 2003; 133: 2003S-7S. PMid:12771354

[29] Radimer K., Bindewald B., Hughes J., Ervin B., Swanson C., and Picciano M.F. Dietary supplement use by US adults: data from the National Health and Nutrition Examination Survey, 1999-2000. Am J Epidemiol. 2004; 160: 339-49. PMid:15286019 http://dx.doi .org/10.1093/aje/kwh207

[30] Bovell-Benjamin A., and Elmubarak E. Diet-nutrition-related cancer prevention knowledge and beliefs of Sudanese in Khartoum: A descriptive study. Open Journal of Preventive Medicine. 2013; 3 (3): 320-328. http://dx.doi.org/10.4236/ojpm.2013.33043

[31] Weinstein N.D., Kwitel A., McCaul K.D., Magnan R.E., Gerrard M., and Gibbons FX. Risk perceptions: Assessment and relationship to influenza vaccination. Health Psychology. 2007; 26: 146151. PMid:17385965 http://dx.doi.org/10.1037/0278-613 3.26.2.146

[32] Elmubarak E., Bromfield E., and Bovell-Benjamin A.C. Focused interviews with Sudanese Americans: perceptions about diet, nutrition, and cancer. Preventive Medicine. 2005; 40(5): 502-509. PMid:15749131 http://dx.doi.org/10.1016/j.ypm ed. 2004.09.021 